\title{
Presynaptic Facilitation Revisited: State and Time Dependence
}

\author{
John H. Byrne ${ }^{1}$ and Eric R. Kandel ${ }^{2}$ \\ 1 Department of Neurobiology and Anatomy, University of Texas Medical School, Houston, Texas 77030, and \\ 2Howard Hughes Medical Institute and Center for Neurobiology and Behavior, College of Physicians and Surgeons of \\ Columbia University, New York, New York 10032
}

The mechanisms underlying short-term presynaptic facilitation, the enhancement of transmitter release from sensory neurons in Aplysia, induced by serotonin ( $5-\mathrm{HT})$, can be divided into two categories: (1) changes in ionic conductances leading to spike broadening and enhancement of $\mathrm{Ca}^{2+}$ influx; and (2) actions on the machinery for transmitter release that are independent of spike broadening and the resulting increases in $\mathrm{Ca}^{2+}$ influx. Spike broadening and the associated enhancement of excitability are induced by the modulation of $\mathrm{K}^{+}$conductances in the sensory neuron. The cellular mechanisms that contribute to the enhancement of release that is independent of spike broadening are not known and may involve vesicle mobilization or other steps in exocytotic release. These two facilitatory actions of 5-HT are mediated by at least two second-messengeractivated protein kinase systems, protein kinase $A(P K A)$ and protein kinase $\mathrm{C}(\mathrm{PKC})$.

These two second-messenger cascades overlap in their contributions to synaptic facilitation. However, their relative contributions to enhancement of transmitter release are not simply synergistic but are state- and time-dependent. The state dependence is a reflection of the synapse's previous history of activity. When the synapse is rested (and not depressed), a brief pulse of 5-HT (lasting from $10 \mathrm{sec}$ to $5 \mathrm{~min}$ ) produces its actions primarily through PKA via both spike broadening- dependent and -independent mechanisms. The broadening primarily involves the modulation of a voltage-dependent $\mathrm{K}^{+}$ current, $I_{\mathrm{KV}}$, with a small contribution by a voltage-independent $\mathrm{K}^{+}$current, $I_{\mathrm{Ks}}$. By contrast, the enhancement of excitability is mediated primarily by the modulation of $I_{\mathrm{KS}}$. As the syrapse becomes depressed with repeated activity, the contribution of PKC becomes progressively more important. As is the case with PKA, PKC produces its action both by broadening the spike via modulation of $I_{K V}$ and by a spike broadeningindependent mechanism.

In addition to being state-dependent, the mechanisms of facilitation are time-dependent. There are differences in the response to 5-HT when it is given briefly to produce short-term facilitation or when the exposure is prolonged. When exposure is brief ( $\leq 5 \mathrm{~min}$ ), PKA dominates. When exposure is prolonged (10-20 min), PKC becomes dominant as it is with depressed synapses. Thus, synaptic plasticity appears to be expressed in several overlapping time domains, and the transition between very short-term facilitation and various intermediate duration phases seems to involve interactive processes between the kinases.

Key words: synaptic facilitation; cAMP; $5-H T$; $K^{+}$channels; learning; Aplysia
The synaptic connections between the sensory neurons of Aplysia and their follower neurons in the gill- and tail-withdrawal reflexes undergo a variety of plastic changes in response to behavioral training procedures that give rise to associative and nonassociative forms of learning and to short- and long-term memory storage associated with each of these forms of learning. For that reason, these synaptic connections have been used as model systems for examining the elementary cellular mechanisms contributing to simple forms of learning and to short- and long-term memory storage (Kandel and Schwartz, 1982; Carew and Sahley, 1986; Byrne, 1987; Hawkins et al., 1993).

In this review, we focus on one form of plasticity in these synaptic connections, short-term heterosynaptic (presynaptic) facilitation, because this form of facilitation has been studied extensively and has provided several of the initial insights into

J.H.B. was supported by National Institute of Mental Health Award K05 MH-00649, NIII Rescarch Grant R01 NS-19895, and Grant F.49620-93-0272 from the Air Force Office of Scientific Research. E.R.K. was supported by the Howard Hughes Medical Institute and by National Institute of Mental Health Grant 1 P50 MH-5000733. We thank Douglas Baxter, Vincent Castellucci, Mark Klein, Robert Hawkins, Shuzo Sugita, Tom Abrams, and Tom Carew for their critical comments on this manuscript. Copyright (C 1996 Society for Neuroscience $0270-6474 / 96 / 160425-11 \$ 05.00 / 0$ learning-related synaptic modulation (Carew and Sahley, 1986; Hawkins et al., 1986; Byrne, 1987). For cxample, studics of Aplysia synapses provided the first evidence for presynaptic (heterosynaptic) facilitation, the process by which activity in one (modulatory) pathway can facilitate transmitter release by another (test) pathway (Kandel and Tauc, 1965; Mintz and Korn, 1991; McGehee et al., 1995). This system also provided the first direct evidence that a second-messenger pathway [CAMP and the cAMP-dependent protein kinase A (PKA)] can regulate the strength of synaptic transmission (Brunelli et al., 1976), and that modulatory transmitters produce some of their actions on synaptic strength by phosphorylating ion channels (Siegelbaum et al., 1982; Shuster et al., 1985; Baxter and Byrne, 1990a). Finally, because the monosynaptic pathway in the gill- and siphon- withdrawal reflexes and the related pathway activated by tail stimuli belong to a reflex system that can be studied on the cellular level, the study of these systems in Aplysia has provided an exceptionally favorable opportunity for relating synaptic changes in specific cells to behavior and its development and to simple forms of learning (Byrne et al., 1993; Hawkins et al., 1993; Carew, 1995).

Studies carried out 30 years ago in the identified cell, R2, of the 
abdominal ganglion of Aplysia demonstrated that a strong synaptic input from one pathway produces heterosynaptic facilitation of transmission in another monosynaptic pathway that lasts for several minutes (Kandel and Tauc, 1965). Similar heterosynaptic facilitation was found later to be recruited for two forms of nonassociative learning in the gill-withdrawal reflex: dishabituation and sensitization (Castellucci et al., 1970; Carew et al., 1971). Sensitization is a form of learning in which an animal learns about the properties of a single, noxious stimulus. When a noxious stimulus is applied to the head or tail of Aplysia, the animal subsequently exhibits increased responsiveness in a variety of elicited defensive reflex responses. Dishabituation is a related form of learning in which the animal, after a noxious stimulus, exhibits enhanced responsiveness in a reflex that previously had been habituated and reduced in its responsiveness after a series of non-noxious stimuli.

Sensitization and dishabituation have been studied in some detail in three reflexes of Aplysia: (1) the gill-withdrawal reflex in response to siphon stimulation; (2) the tail-withdrawal reflex in response to tail stimulation; and (3) the siphon-withdrawal reflex in response to tail stimulation. Both head and, more commonly, tail stimuli have been used as noxious stimuli to produce either sensitization or dishabituation. Thus, training for behavioral sensitization or dishabituation using tail (or head) shock lcads to heterosynaptic facilitation of connections between identified sensory and motor neurons of the gill- and tail-withdrawal reflex (Castellucci et al., 1970; Kupfermann et al., 1970; Walters et al., 1983). Quantal analysis of evoked and spontaneous transmitter release at these synaptic connections, both in the ganglion and in dissociated cell culture, revealed that heterosynaptic facilitation is presynaplic in origin (Castellucci and Kandel, 1976; Dale et al., 1988) and can be induced by at least two different types of modulatory neurons that act on the sensory neurons: serotonergic neurons and the L29 cells, which release a transmitter that is still unidentified. The small cardiac peptide (SCP) also facilitates the transmission, but the cells that mediate this facilitation have not been identified. The serotonin (5-HT)-mediated transmission has been studied most extensively because it is particularly important. Reducing the intracellular levels of 5-HT by addition of the neurotoxin 5,7-dihydroxytryptamine (5-7 DHT) blocks the ability of tail stimuli to sensitize the gill-withdrawal reflex response (Glanzman et al., 1989). In addition, 5-HT simulates the actions of the tail stimulus, both in facilitating the strength of the connections between the sensory and motor neurons and in increasing strength of the reflex response (see Brunelli et al., 1976; Walters et al., 1983; Abrams et al., 1984).

Several studies have implicated cAMP as a second messenger in presynaptic facilitation. First, it was found that injection of cAMP or PKA into the presynaptic sensory neuron simulates the facilitation produced by tail shock or application of 5-HT (Brunelli et al., 1976; Castellucci et al., 1980; Klein, 1993). A similar simulation was produced by bath application of forskolin (Klein, 1993). Conversely, inhibitors of PKA block facilitation (Castellucci et al., 1982; Ghirardi et al., 1992). Second, it was found that tail stimuli or shock of peripheral nerves, as well as 5-HT (or SCP), produces an increase in cAMP levels in the sensory neurons (Bernier et al., 1982; Castellucci et al., 1982; Abrams et al., 1984; Ocorr and Byrne, 1985, 1986; Ocorr et al., 1985, 1986). Similar results on the intact ganglia were obtained earlier by Cedar and Schwartz (1972) and Cedar et al. (1972).

The facilitation produced by $5-\mathrm{HT}$ and by tail stimuli was found to lead both to a broadening of the presynaptic spike and to an enhancement in membrane excitability, as reflected by a lower threshold for the action potential and less frequency adaptation to a prolonged pulse of injected current (Klein and Kandel, 1978, 1980; Walters et al., 1983; Klein et al., 1986; Baxter and Byrne, 1990a). These findings prompted a search for the substrates of PKA that might contribute to this spike broadening and enhanced excitability. Using two-electrode voltage-clamp recordings, it was found that 5-IIT and cAMP modulated a novel $\mathrm{K}^{+}$current that had only a slight voltage dependence (Klein et al., 1982; Pollock et al., 1985; Baxter and Byrne, 1989). Single-channel recordings identified a specific channel, the S ("serotonin")-type $\mathrm{K}^{+}$channel, which is modulated by 5-HT, cAMP (Siegelbaum et al., 1982), and PKA (Shuster et al., 1985). The elementary conductance of the channel was not modulated by $5-\mathrm{HT}$; rather, $5-\mathrm{HT}$ reduced the number of channels open in a given patch of membrane. Because 5-HT and tail stimuli produced a broadening of the spike and enhanced excitability, both of these changes were attributed to a reduction in the $\mathrm{K}^{+}$current through the S-type channel, designated $I_{\mathrm{KS}}$ (Klein et al., 1980, 1982).

These findings were combined to devise a cellular model for short-term facilitation (Klein and Kandel, 1980; Klein et al., 1980; Kandel and Schwartz, 1982; Baxter and Byrne, 1989) (see Fig. 1). According to this model, a single, brief sensitizing stimulus leads to the activation of facilitatory intcrncurons, resulting in the release of 5-HT (and other modulatory neurotransmitters), which produces presynaptic facilitation of the connections between sensory and motor neurons. 5-HT increases the rate of synthesis of cAMP, leading to the activation of PKA, phosphorylation of the S-type $\mathrm{K}^{+}$channels, and reduction of their conductance, $g_{\mathrm{KS}}$. The reduction of $I_{\mathrm{KS}}$ via PKA leads to an increase in excitability of the sensory neurons, which is reflected in a greater number of spikes that is elicited in response to a $0.5-1 \mathrm{sec}$ stimulus (data not shown in Fig. 1A) (Klein et al., 1986; Baxter and Byrne, 1990a; Ghirardi et al., 1992; Goldsmith and Abrams, 1992). In addition, each spike elicited in a sensory neuron after a sensitizing stimulus is broader (Fig. 1A3) and results in increased influx of $\mathrm{Ca}^{2+}$ via $\mathrm{Ca}^{2+}$ channels $\left(g_{\mathrm{Ca}}\right)$ and enhanced transmitter release. The enhanced transmitter release leads, in turn, to enhanced EPSPs in the motor neuron that could contribute (together with changes in other parts of the neural circuit) to an enhanced behavioral response (i.e., to sensitization) (Kandel and Schwartz, 1982).

This model was developed initially for presynaptic facilitation related to short-term sensitization. It was extended later to longterm sensitization (Kandel and Schwartz, 1982; Goelet et al., 1986; Zhang et al., 1994). Thus, whereas a single tail shock leads to reflex sensitization lasting minutes, four to five successive tail stimuli lead to sensitization lasting for more than a day; further stimulus repetition leads to sensitization lasting weeks. Both the functional facilitation of the sensory-to-motor synapse and its structural alterations - the growth of new synaptic connectionsare correlated with long-term sensitization (Frost et al., 1985; Bailey and Chen, 1988a,b; Lee et al., 1995). Moreover, as is the case for short-term sensitization, long-term sensitization training can be simulated by applications of 5-HT (Montarolo et al., 1986; Emptage and Carew, 1993) or by stimulation of peripheral nerves (Zhang et al., 1994). Whereas a single, brief pulse of 5-HT produces short-term facilitation lasting minutes, five pulses of 5-HT produce long-term facilitation lasting 1 or $2 \mathrm{~d}$. Long-term differs from short-term facilitation in requiring protein and RNA synthesis (Montarolo et al., 1986) and in giving rise to the growth of new synaptic connections (Bailey and Chen, 1988a,b; Glanzman et al., 1990). Nevertheless, long-term facilitation resembles 
short-term facilitation in being induced by both 5-HT and cAMP and in involving both enhancement of transmitter release and enhanced presynaptic excitability (Dale et al., 1987). Moreover, the major current modulated during long-term facilitation appears to be $I_{\mathrm{KS}}$ (Scholz and Byrne, 1987). Thus, long-term facilitation seems to be an extension, in a protein synthesis- and RNA synthesis-dependent manner, of at least some aspects of shortterm facilitation (Sweatt and Kandel, 1989). Independent support for the mechanistic relationship between short- and long-term facilitation has been obtained by the finding that both short- and long-term facilitation emerge at the same time during development, a time at which 5-HT already can activate the cAMP-PKA pathway fully but as yet cannot activate the protein kinase $\mathrm{C}$ (PKC) pathway (Carew et al., 1989).

Short-term facilitation, however, has proven to be more complex than long-term facilitation. Specifically, three additional components appear to contribute to short-term facilitation as a function of both the state of the synapses and the time after exposure to 5-HT. First, 5-HT has been found to modulate transmitter release independently of spike broadening (Gingrich and Byrne, 1984, 1985, 1987; Hochner et al., 1986b; Braha et al., 1990; Dale and Kandel, 1990; Ghirardi et al., 1992; Pieroni and Byrne, 1992; Sugita et al., 1992, 1994c; Klein, 1993, 1994a; Stark and Carew, 1994).

Second, short-term facilitation has been found to recruit an additional second-messenger system, PKC, as a function of synaptic state and time of exposure to 5-HT (Braha et al., 1990; Sacktor and Schwartz, 1990; Ghirardi et al., 1992; Sossin and Schwartz, 1992; Sugita et al., 1992, 1994a).

Third, aside from $I_{\mathrm{KS}}$, other currents are modulated, one of which, the voltage-dependent current, $I_{\mathrm{KV}}$, has been found to contribute critically to spike broadening (Baxter and Byrne, 1989, 1990a; Walsh and Byrne, 1989; Critz et al., 1991; Goldsmith and Abrams, 1992; Hochner and Kandel, 1992; Sugita et al., 1992, 1994a; Braha et al., 1993; White et al., 1994).

Here we review the experiments that have led to the findings of three additional steps in presynaptic facilitation and present an updated view (see Figs. 2, 3) of how 5-HT induces presynaptic facilitation as a function of the state of the synapse and of the time of exposure to 5-HT. On the basis of these findings, we then examine the new insights that have emerged as a result of experimental progress over the last decade.

\section{DUAL CONTROL OF SYNAPTIC FACILITATION THROUGH SPIKE BROADENING-DEPENDENT AND -INDEPENDENT MECHANISMS}

The initial clue to the existence of additional facilitatory mechanisms aside from spike broadening in short-term facilitation came from the discovery that the efficacy of mechanisms that contribute to presynaptic facilitation vary as functions of the state of the synapse. Although several critical aspects of the rested synapse could be explained qualitatively in the context of the model shown in Figure 1 (compare Figs. 1, 2A), additional mechanisms had to be postulated to explain facilitation of the synapse after repeated low-frequency homosynaptic activity in the presynaptic neuron.

The first evidence for this additional complexity came from mathematical modeling and computer simulations showing that once an action potential becomes greatly prolonged, further facilitation cannot occur by further spike broadening but must recruit a process in addition to spike broadening. These modeling studies suggested that spike broadening alone was insufficient to account fully for presynaptic facilitation and that this was partic-
An Early View of Presynaptic Facilitation

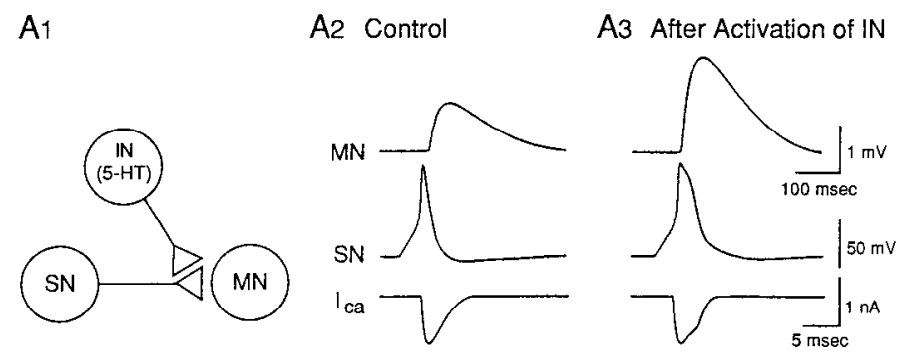

B

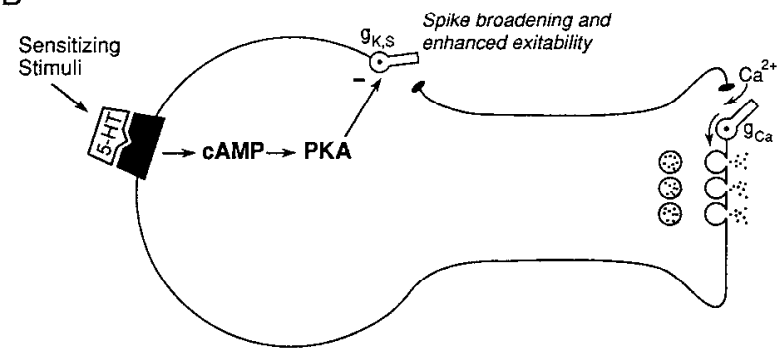

Figure 1. A, An early view of heterosynaptic facilitation that contributes to sensitization. $A 1$, The synaptic connection between the sensory neuron $(S N)$ and the motor neuron $(M N)$ is enhanced by a facilitatory interneuron $(I N)$ that releases 5-HT. $A 2, A 3$, Stylized representations of control and facilitated responses. $A$ ? Control F.PSP. An action potential in the SN leads to an influx of $\mathrm{Ca}^{2+}\left(I_{C a}\right)$, the release of transmitter, and a subsequent EPSP in the MN. A3, EPSP produced by an action potential in the SN after neuron IN had been activated. The EPSP amplitude is larger because the facilitatory IN leads to a reduction in $\mathrm{K}^{+}$conductance in the $\mathrm{SN}$ and a subsequent broadening of the action potential and enhancement of $I_{\mathrm{Ca}}$ caused by an increase in $\mathrm{Ca}^{2+}$ channel conduclivily, $g_{\mathrm{Ca}}$. The enhanced influx of $\mathrm{Ca}^{2+}$ leads to enhanced transmitter release and an enhanced EPSP. $B$, An early view of the molecular mechanisms underlying 5-HT-induced, short-term synaptic facilitation. In this scheme, cAMP is the only second messenger activated by 5 -HT in the sensory neuron. cAMP-induced reduction of S-type $\mathrm{K}^{+}$channel conductivity, $g_{\mathrm{K}, \mathrm{s}}$, is considered to underlie the modulation of two physiological properties of the sensory neuron: spike broadening and enhanced excitability. Spike broadening is believed to play a key role in synaptic facilitation of sensorimotor connections as shown in $A$.

ularly apparent when the demand on transmitter release becomes greal. To maintain or augment the transmitter pool, 5-HT must act directly to mobilize transmitter vesicles to the active zone (Gingrich and Byrne, 1984, 1985, 1987; Gingrich et al., 1988).

The first experimental evidence for a second process in facilitation (one independent of spike broadening) came from experiments that demonstrated that 5-HT can produce facilitation independent of spike broadening when the demand on transmitter release becomes great (Hochner et al., 1986a,b). Explorations of how the duration of the presynaptic action potential, controlled by voltage-clamping the presynaptic ccll, controls transmitter rclcase in the presence or absence of 5-HT showed that in the absence of $5-\mathrm{HT}$, even increases of $10-30 \%$ in the duration of the action potential produced significant increases in EPSP amplitude, which is indicative of presynaptic facilitation. Preventing broadening of the presynaptic action potential by voltage-clamping the presynaptic neuron reduced the facilitation produced by 5-HT (Hochner et al., 1986a,b). These results were consistent with findings to emerge later in studies of the squid giant synapse that even slight 
broadening in the presynaptic spike by 10 or $20 \%$ produces large increases (50-100\%) in transmitter release (Augustine, 1990).

In the course of this work, it was discovered that an additional set of processes also contributes to facilitation (Hochner et al., $1986 \mathrm{a}, \mathrm{b})$. When the sensory neuron is activated repeatedly, it undergoes a striking decrease in synaptic strength, called "homosynaptic depression," caused by a progressive decrease in the amount of transmittcr released by cach action potential. In the presence of homosynaptic depression, prolonging the duration of the depolarizing voltage-clamp command had little effect on transmitter release. Nevertheless, 5-HT was still capable of enhancing release. Moreover, once 5-HT enhanced release, increases in the duration of the presynaptic command again became highly effective in enhancing release further. Consistent with the mathematical model (Gingrich and Byrne, 1985, 1987), these studies suggested that when transmitter release becomes depressed (presumably because of a limited supply of transmitter) (Bailey and Chen, 1988c), 5-HT is capable of modulating some aspects of release not available to spike broadening alone. For spike broadening to increase release in depressed synapses, 5-HT first must recruit other processes necessary for facilitation. These findings suggested that two major processes contribute to facilitation at all times: (1) a spike-broadening process that leads to increased $\mathrm{Ca}^{2+}$ influx and, consequently, enhanced release; and (2) a $\mathrm{Ca}^{2+}$-independent process related to some step in the release process, perhaps mobilization or exocytosis itself, that does not involve $\mathrm{Ca}^{2+}$ influx (Hochner et al., 1986a,b; Braha et al., 1990). Although the two processes were thought to have overlapping domains, spike broadening was thought to predominate in the nondepressed synapse, whereas the spike broadening-independent process was thought to become important as an additional step in facilitation at the depressed synapse.

Studies of learning traditionally had distinguished between sensitization, the enhancement of a reflex response by a noxious stimulus, and dishabituation, the enhancement by a noxious stimulus of a reflex that previously had been habituated. That a second process, independent of spike broadening and increased $\mathrm{Ca}^{2+}$ influx, contributes to presynaptic facilitation at the depressed synapse suggested that this behavioral distinction is also present at the cellular level (Hochner et al., 1986a). That parallel is now even more clearly visible by the finding that dishabituation and sensitization emerge as separate processes during development in Aplysia (Rankin and Carew, 1988). For example, short-term dishabituation of the gill-withdrawal reflex emerges at an earlier time in development than does short-term sensitization. Moreover, lower concentrations of 5-HT are required to produce facilitation of depressed synapses than are required to facilitate nondepressed synapses (Fmptage and Carew, 1994; Fmptage et al., in press). The mechanism for this differential effect of 5-HT is not known.

The finding that 5-HT activates mechanisms in addition to spike broadening for enhancing transmitter release led to a reexamination of the relationship between spike broadening and transmitter release. The initial correlation between transmitter release at the terminal and spike broadening was based on the recording of action potential duration (and later of $\mathrm{Ca}^{2+}$ influx) into the cell body of the presynaptic neuron (Blumenfeld et al., 1990). To obtain data directly from the presynaptic terminals rather than from the cell body, Eliot et al. (1993) studied synapses between sensory and motor neurons reconstructed in dissociated cell culture, imaging $\mathrm{Ca}^{2+}$ influx into the presynaptic terminals in response to action potentials. Using synapses that received minimal previous stimulation, they found that 5-HT enhanced $\mathrm{Ca}^{2+}$ influx through dihydropyridine-insensitive $\mathrm{Ca}^{2+}$ channels near release sites in parallel with spike broadening. The influx was correlated with the degree of facilitation. Although the duration of the action potential in the presynaptic terminals could not be measured, parallel experiments in the cell body showed a direct relationship between the 5-HT-induced increase in $\mathrm{Ca}^{2+}$ influx and spike duration (Eliot et al., 1993). These results provided cvidence that when spike broadening occurred, there was a sufficient increase in $\mathrm{Ca}^{2+}$ influx into the presynaptic terminals to contribute significantly to presynaptic facilitation.

Parallel studies of the relationship between somatic spike broadening and transmitter release were performed in intact pleural-pedal ganglia (Sugita et al., 1994c) and in dissociated cell culture (Klein, 1994a). Using low concentrations of $\mathrm{K}^{+}$channelblocking agents such as tetraethylammonium or 4-aminopyridine, (4-AP), these studies showed an approximately linear relation between the increase in spike duration and the increase in the amplitude of synaptic potentials. Moreover, there was a strong temporal correlation between the development of 4-AP-induced spike broadening and synaptic facilitation, which is consistent with the idea that spike broadening can contribute directly to facilitation of the synaptic connections.

The facilitation induced by $5-\mathrm{HT}$ was found to develop rapidly and reach a peak within 3 min after its application. By contrast, the spike broadening induced by $5-\mathrm{H} T$ did not reach its peak until 12 min after its application (Sugita et al., 1994c). Comparison of 4-AP-induced and 5-HT-induced spike duration and synaptic enhancement indicated that, even in the nondepressed synapse, a component of the observed 5-HT-induced facilitation at 3 and 6 min after application was independent of the increase in spike duration (Klein, 1994a; Sugita et al., 1994c).

These conclusions have been supported by studies indicating that depending on the precise experimental conditions, including the concentration of 5-HT and the duration of exposure, either of the two components for facilitation can dominate. Under some circumstances, facilitation of even nondepressed synapses can occur in the absence of spike broadening. For example, in the absence of action potentials, 5-HT leads to enhanced spontaneous transmitter release from sensory neurons in culture (Dale and Kandel, 1990). This enhanced release is independent of $\mathrm{Ca}^{2+}$ influx (see also Ghirardi et al., 1992). In a novel culture system in which sensory and motor neurons make direct soma-to-soma contacts, it was shown that 5-HT can produce cAMP-mediated facilitation that does not require spike broadening (Klein, 1993, 1994b). Similarly, during development 5-HT can induce facilitation and changes in excitability (presumably acting via cAMP), with only minimal spike broadening $(\leq 10 \%)$. Major spike broadening emerges later (Marcus and Carew, 1990, 1992; Stark and Carew, 1994).

These studies suggest that a spike broadening-independent process (perhaps a direct enhancement of transmitter mobilization or exocytosis) is a central mechanism for facilitation. Spike broadening seems to represent an additional amplification mechanism functioning to enhance the basic capability for facilitation. Although the two mechanisms can be dissociated with certain protocols, it is likely that both mechanisms contribute significantly to behavioral sensitization (Stark et al., in press). 


\section{RECRUITMENT BY 5-HT OF TWO SECOND MESSENGERS, PKA AND PKC, IN A STATE- AND TIME-DEPENDENT MANNER}

The recruitment by 5 -HT of a second facilitatory process, independent of spike broadening, led to the search for the second messengers that might mediate this process. PKC became a candidate for a second messenger when it was found that phorbol esters enhance release at the sensory neuron-motor neuron synapse and that they can do so even when release is very depressed (Hochner et al., 1985; Braha et al., 1990). In support of these findings, it was found that both sensitizing stimuli and 5-HT lead to the translocation to the membrane of the $\mathrm{Ca}^{2+}$-dependent isoform of PKC, one of two isoforms of PKC present in sensory neurons (Sacktor and Schwartz, 1990; Kruger et al., 1991; Sossin and Schwartz, 1992; Braha et al., 1993; Sossin et al., 1993), both of which are activated by phorbol esters. cAMP did not translocate PKC, suggesting that the CAMP/PKA pathway and the PKC pathway are independent (Sacktor and Schwartz, 1990). These findings suggest that, in addition to PKA, presynaptic facilitation also involves PKC.

In dissociated cell culture, low concentrations of phorbol esters facilitate evoked release from the sensory neurons without causing spike broadening (Hochner et al., 1985; Braha et al., 1990), suggesting that at least one of the actions of PKC is a spike broadening-independent step in release. That the 5-HT-induced increase in spontaneous release (which occurs in culture in the absence of $\mathrm{Ca}^{2+}$ influx) is blocked by $\mathrm{H} 7$, a kinase inhibitor that appears to be relatively specific for PKC in Aplysia (Conn et al., 1989; Ghirardi et al., 1992), is consistent with this idea. By contrast, inhibitors of cAMP do not block the 5-HT-induced increase in spontaneous release (Ghirardi et al., 1992).

To test the relative contribution of the two kinases to nondepressed synapses and depressed synapses, the effects of inhibitors were examined. It was found that the degree to which the two kinases contribute to facilitation depends on the degree of the preexisting depression. When the synapse was not depressed, a single, $5 \mathrm{~min}$ pulse of 5 -HT that produced short-term facilitation lasting minutes was blocked completely by inhibitors of PKA but was not affected by $\mathbf{H} 7$, an inhibitor of PKC. By contrast, as the synapse bccamc more depressed, the inhibitor of PKC bccame progressively more effective in blocking 5-HT-induced short-term facilitation (Braha et al., 1990; Goldsmith and Abrams, 1991; Ghirardi et al., 1992). Finally, when the synapse is very depressed (to $\sim 10 \%$ of control), the inhibitors of PKA have their least significant effect, blocking only $30 \%$ of the facilitation, whereas inhibitors of PKC block the facilitation almost completely. Independent evidence for the role of cAMP independent of spike broadening is provided by the facilitation by photorelease of "caged" cAMP of synapses that are moderately depressed to levels at which spike broadening is ineffective in enhancing release. In addition to these state-dependent effects, the ability of the inhibitors to attenuate 5-HT-induced facilitation was also dependent on the time after the application of 5-HT at which the synapse was tested. PKA inhibitors were more effective in attenuating 5-HT-induced facilitation on the first few responses after 5-HT application than were inhibitors of PKC (Braha et al., 1990; Hochner and Kandel, 1992). Conversely, Sugita et al. (1992) found that inhibitors of PKC were more effective in attenuating 5-HT-induced facilitation at later times.

Examination of the kinetics of spike broadening in response to a prolonged application of 5-HT showed that this process appears to have at least two components: a rapidly developing component evident within $36 \mathrm{~min}$, and a slowly developing component over the next 6-10 min (Hochner and Kandel, 1992; Stark et al., 1992; Sugita et al., 1992, 1994c; Stark et al., in press). Thus, a single, brief pulse of 5-HT lasting $<5 \mathrm{~min}$, typically used in cellular experiments to produce short-term facilitation, induces maximal facilitation but not maximal spike broadening. By contrast, at the end of a $12 \mathrm{~min}$ exposure to 5-HT, when the 5-HT-induced spike broadening had reached its peak, broadening was estimated to account for a greater percentage of the observed facilitation. These results suggested that although both spike broadeningdependent and -independent mechanisms can play important roles in the 5-HT-induced synaptic facilitation, their relative contributions vary not only with synaptic state but also with the total duration of exposure to 5-HT. These time-dependent effects are attributable to the differences in the kinetics of recruitment of PKA and PKC.

Thus, in the continuous presence of 5-HT over many minutes, inhibitors of PKA and PKC vary in their effectiveness in blocking spike broadening as a function of time after the continuous application of 5-HT. Consistent with the finding in cell culture that a 5 min pulse of 5-HT produces facilitation that is blocked by inhibitors of PKA, pre-exposure to staurosporine, an inhibitor of PKC, has little effect on 5-HT-induced spike broadening in the intact ganglion after a 3 min exposure of 5-HT. By contrast, staurosporine strongly inhibits the 5 -HT-induced spike broadening at later times (Sugita et al., 1992).

\section{MODULATION BY 5-HT OF TWO $\mathrm{K}^{+}$CURRENTS THAT PRODUCE SPIKE BROADENING AND INCREASED EXCITABILITY}

The contribution of specific ionic currents to spike broadening was studied initially by simulating action potentials in the sensory neurons by applying depolarizing commands every 10-30 sec (Klein and Kandel, 1980; Klein et al., 1982; Pollock et al., 1985). With this protocol, at least three $\mathrm{K}^{+}$currents are activated: the S-type $\mathrm{K}^{+}$current $\left(I_{\mathrm{KS}}\right)$, the fast, transient outward current $\left(I_{\mathrm{KA}}\right)$, and the slower, transient-activated current $\left(I_{\mathrm{KV}}\right)$. However, $I_{\mathrm{KV}}$ exhibits cumulative inactivation and is mostly inactivated under this protocol. By stimulating less frequently, less inactivation of outward current is produced. Under these conditions, it was found that, in addition to modulating $I_{\mathrm{KS}}, 5-\mathrm{HT}$ modulates $I_{\mathrm{KV}}$, a current that is more important for spike broadening than $I_{\mathrm{KS}}$ (Baxter and Byrne, 1989). The modulation produced by 5-HT slows both the activation and the inactivation kinetics of $I_{\mathrm{KV}}$ (White et al., 1994). This causes a decrease in the net outward current elicited at the beginning of a voltage-clamp pulse and an increase at the end of the pulse. This effect develops slowly and becomes stable $\sim 10 \mathrm{~min}$ after application of 5-HT.

Because of overlapping responses to electrical and pharmacological stimulation, it has been difficult to be certain of exactly how much the modulation of $I_{\mathrm{KS}}$ and $I_{\mathrm{KV}}$ contributes to spike broadening and to the excitability change. One evaluation of the relative contribution of $I_{\mathrm{KS}}$ and $I_{\mathrm{KV}}$ has come from an analysis of Hodgkin-Huxley-type mathematical models of the sensory neurons. These models indicated that $I_{\mathrm{Ks}}$ plays a dominant role in regulating excitability but only a modest role in spike broadening. By contrast, $I_{\mathrm{KV}}$ plays a dominant role in regulating spike broadening (Baxter and Byrne, 1990b; Byrne et al., 1990; Canavier et al., 1991; Belkin et al., 1992).

Studies using activators and inhibitors of PKA and PKC indicated that the 5-HT-induced enhancement of excitability in sensory neurons is mediated almost exclusively by PKA (Klein et al., 
1986; Baxter and Byrne, 1990a; Ghirardi et al., 1992; Goldsmith and Abrams, 1992). 4 $\beta$-Phorbol-12,13-diacetate, an activator of PKC, produces little or no enhancement of excitability (Braha, 1990; Sugita et al., 1992; Braha et al., 1993), and inhibitors of PKC do not inhibit the enhancement of excitability produced by 5-HT (Goldsmith and Abrams, 1992; Hochner and Kandel, 1992; Sugita et al., 1992). By contrast, both PKA and PKC can produce a substantial spike broadening through $I_{\mathrm{KV}}$ equivalent to that produced by 5 -HT. Conversely, the substantial spike broadening produced by 5-HT can be suppressed by inhibitors of either PKA or PKC (Goldsmith and Abrams, 1992; Sugita et al., 1992). Thus, whereas modification of excitability reflects the singular action of PKA, $I_{\mathrm{KV}}$ appears to be regulated jointly by PKA and PKC, However, the actions of the two kinases appear to vary as a function of the time of exposure to 5-HT (Braha et al., 1993). The modulatory action of cAMP on $I_{\mathrm{KV}}$ is fast, and a major part of the rapidly developing component of spike broadening appears to be dependent on PKA (Baxter and Byrne, 1990a; Ghirardi et al., 1992; Hochner and Kandel, 1992). For example, a PKA inhibitor blocks $75 \%$ of this rapidly developing component, and a PKC inhibitor blocks $25 \%$ of it (Goldsmith and Abrams, 1992; Hochner and Kandel, 1992; Sugita et al., 1992). In addition, intracellular injection of an analog of cAMP, Sp-cAMPS, or extracellular application of a membrane-permeable cAMP analog, 8-bromocAMP, produces spike broadening comparable with that induced by 5 -HT within $3 \mathrm{~min}$ (Baxter and Byrne, 1990a; Hochner and Kandel, 1992; Sugita et al., 1994b). By contrast, the modulatory effects of PKC on $I_{\mathrm{KV}}$ develop slowly and become stable more than $\sim 10$ min after its application (Sugita et al., 1994a).

Thus, whereas the rapid early action of $5-\mathrm{HT}$ is mediated to a large degree by PKA, the slowly developing component of 5-HTinduced spike broadening evident after continuous exposure to 5 - HT for $>5 \mathrm{~min}$ is attributable primarily to the modulation of $I_{\mathrm{KV}}$ by PKC. This slow component of spike broadening is well mimicked by phorbol esters and is blocked by staurosporine (Marcus and Carew, 1992; Sugita et al., 1992).

We have focused only on two currents, $I_{\mathrm{KV}}$ and $I_{\mathrm{KS}}$, because they have an important role in facilitation. But both PKA and PKC also modulate other currents in the sensory neuron. These include a slow component of $I_{\mathrm{KCa}}$, designated $I_{\mathrm{KCaS}}$, modulated by PKA (Walsh and Byrne, 1989; Goldsmith and Abrams, 1992; Hochner and Kandel, 1992; Sugita et al., 1994a). Modulation of $I_{\mathrm{KCaS}}$ makes only a small contribution to 5-HT-induced enhancement of excitability (Canavier et al., 1991). Similarly, 5-HT and PKC cause increases in a nifedipine-sensitive $\mathrm{Ca}^{2+}$ current (Edmonds et al., 1990; Braha et al., 1993). Although modulation of this current is relatively small compared with the modulation of $I_{\mathrm{KV}}$, it is plausible that an increase in $\mathrm{Ca}^{2+}$ current also contributes to spike broadening. The modulation of this current by $5-\mathrm{HT}$ is slow to develop (Boyle et al., 1984; Braha et al., 1993; Klein, 1994b).

\section{AN UPDATED MODEL FOR SHORT-TERM PRESYNAPTIC FACILITATION}

In the process of testing and updating the models of the $1980 \mathrm{~s}$, several important new insights have emerged. These are summarized in Figures 2 and 3, which update our understanding of short-term facilitation.

At least two second-messenger protein kinases contribute to enhancement of transmitter release: PKA and PKC (Braha et al., 1990, 1993; Sugita et al., 1992). The existence of these two secondmessenger-activated kinases implies that there are two different

\section{State Dependence}

\section{A Non-Depressed Synapse}

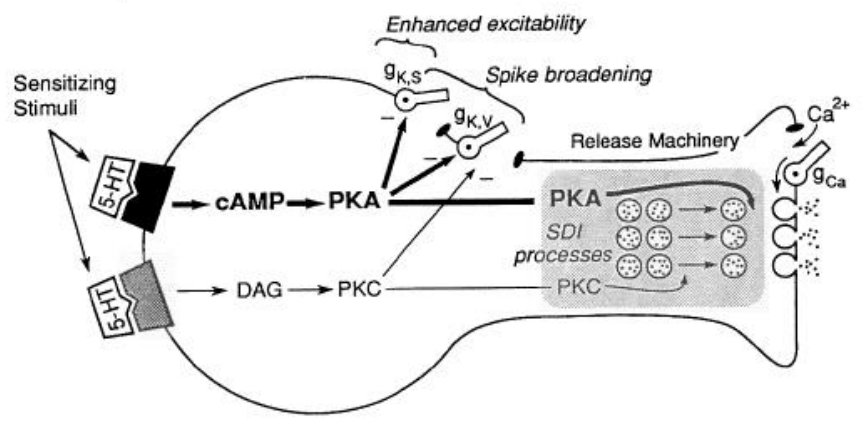

\section{B Depressed Synapse}

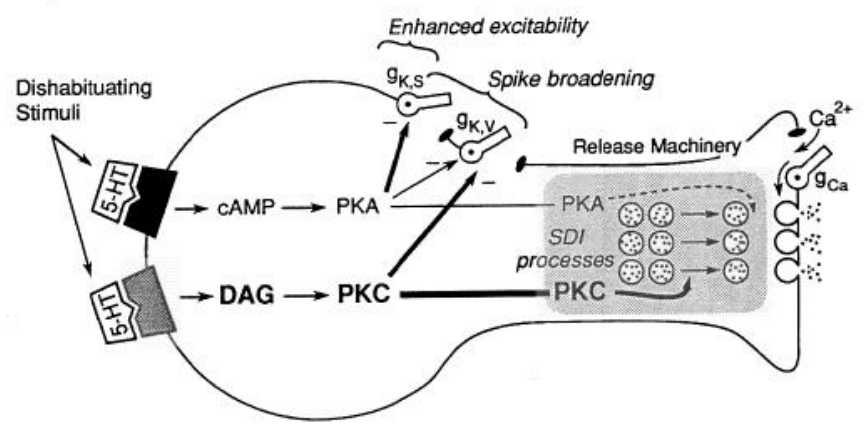

Figure 2. Current model of a sensory neuron that depicts the multiple processes for facilitation and their state dependence. 5-HT released from the facilitatory neuron (Fig. 1A1) binds to at least two distinct classes of receptors on the outer surface of the membrane and leads to the transient activation of two intracellular second messengers, DAG and cAMP. These second messengers, acting through their respective kinases (PKC and $P K A$ ), affect multiple cellular processes, the combined effects of which lead to enhanced transmitter release when a subsequent action potential is fired in the sensory neuron. $A$, In nondepressed synapses, the cAMPsignaling pathway plays a predominant role in facilitation through modulation of membrane currents and through modulation of a spike-duration independent $(S D I)$ process that presumably involves some aspect of the release mechanism itself. $B$, In synapses depressed by previous activity, the DAG-signaling pathway plays a dominant role in facilitation by engaging the SDI process and mobilizing vesicles from a reserve or storage pool. PKA cannot facilitate a depressed synapse. Thus, PKC and PKA appear to affect the SDI process at different loci. Positive $(+)$ and negative $(-)$ signs indicate enhancement and suppression of cellular processes, respectively. Thin lines and smaller lettering indicate weaker effects than solid lines and larger lettering.

second-messenger-synthesizing enzymes and presumably different guanosine triphosphate-binding proteins (Fig. 2A). This is most consistent with the suggestion that 5 -HT acts on at least two types of 5-HT receptors of the sensory neuron (Mercer et al., 1991). One receptor is thought to be coupled to adenylyl cyclase, leading to an increase in the level of cAMP and the activation of a PKA pathway (Bernier et al., 1982; Abrams et al., 1984; Ocorr and Byrne, 1985; Ocorr et al., 1986; Bacskai et al., 1993). The other receptor presumably is coupled to phospholipase $\mathrm{C}$, causing the formation of diacylglycerol (DAG) and the activation of PKC (Braha, 1990; Sacktor and Schwartz, 1990; Sugita et al., 1992; Braha et al., 1993).

These two kinases have overlapping spheres of action. Both act on transmitter release in two ways: (1) via a $\mathrm{Ca}^{2+}$-dependent 


\section{Time Dependence}

\section{A Brief exposure to $5-\mathrm{HT}$}

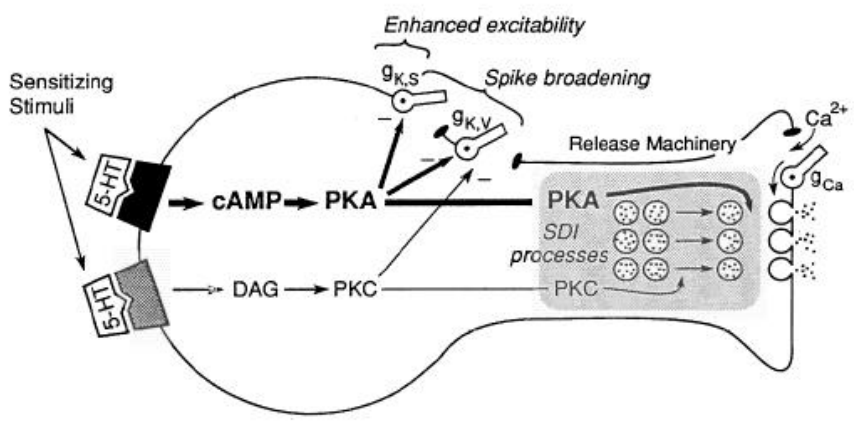

\section{B Prolonged exposure to $5-\mathrm{HT}$}

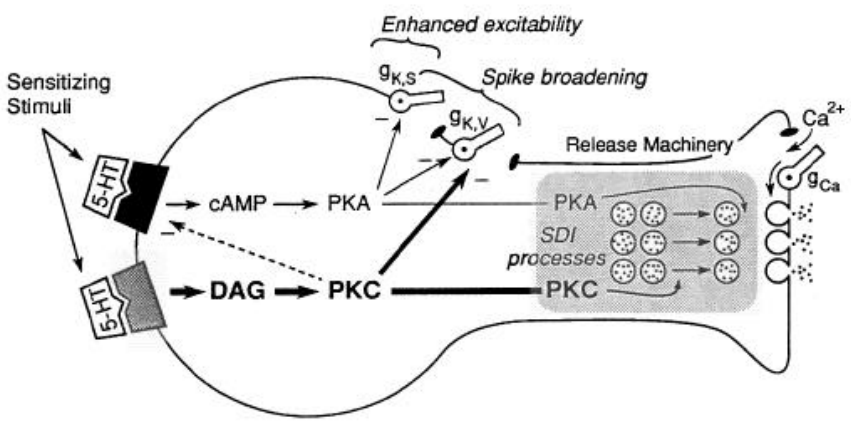

Figure 3. Current model for the time dependence of short-term synaptic facilitation produced by 5-HT. $A$, At early times and with brief applications $(<5 \mathrm{~min}), \mathrm{PKA}$ plays a primary role in 5 -HT-induced synaptic facilitation through the modulation of membrane currents and the SDI processes. $B$, At later times and with more prolonged exposure to 5-HT, PKC plays a dominant role in 5-HT-induced maintenance of facilitation by spike broadening via the modulation of $I_{\mathrm{KV}}$ and the SDI processes. Recent results suggest that $\mathrm{PKC}$ can downregulate the 5-HT-induced increase in cAMP, perhaps via action on the receptor coupled to adenylyl cyclase (dashed line).

process resulting from spike broadening; and (2) via a spike duration-independent (SDI) mechanism.

We now have a good understanding of the mechanisms contributing to spike broadening and the related excitability change. Spike broadening is mediated by two major currents, predominantly by $I_{\mathrm{KV}}$ with a minor contribution from $I_{\mathrm{KS}}$. In addition, $I_{\mathrm{KS}}$ mediates all (or almost all) of the excitability change. Whereas $I_{\mathrm{KV}}$ is modulated by both PKA and PKC, $I_{\mathrm{KS}}$ is modulated only by PKA.

By contrast, we still do not know how the spike broadeningindependent facilitation mechanisms work. One possibility is that PKA and PKC have a direct action on vesicle mobilization or exocytosis. Alternatively, either or both of these two kinases could modulate as yet uncharacterized $\mathrm{Ca}^{2+}$ channels localized to the active zones (Klein, 1994b). Independent of its detailed mechanisms, this spike broadening-independent mechanism appears to be an important component of facilitation. The modulation of spike duration seems to serve as an additional step to amplify release further (Fig. $2 A$ ).

The finding that the two protein kinases, which contribute to presynaptic facilitation, do not simply act interchangeably or synergistically but contribute in a state- and time-dependent manner is of particular interest. This dependence is important not only from a cell biological point of view, but it is potentially important also from a behavioral perspective. It has been known for some time that even simple forms of learning, such as dishabituation and sensitization, are highly dependent on the parameters of the particular paradigm used, such as the intensity and duration of the test and sensitizing stimuli. The studies of presynaptic facilitation illustrate, on the level of a single synaptic connection, that cellular processes contributing to dishabituation and sensitization are themselves dependent on state and time.

The surprising discovery that facilitation is state-dependent has introduced a novel dimension into our thinking about synaptic plasticity, a dimension that is particularly interesting considering its parallel to the state dependence of the reflex enhancement that gives rise to sensitization or dishabituation. Thus, in response to a single, brief tail shock or a single, brief pulse of 5 -HT lasting $\leq 5$ min, the synaptic facilitation of a nondepressed synapse recruited by sensitization appears to be mediated primarily by the cAMP/ PKA pathway (Ghirardi et al., 1992; Sugita et al., 1994c). Such facilitation is well simulated by activators of PKA (forskolin) and analogs of cAMP (Ghirardi et al., 1992; Klein, 1993); this facilitation is blocked by inhibitors of PKA, and it is unaffected by inhibitors of PKC (Ghirardi et al., 1992). This dependence on PKA is consistent with the finding that 5-HT produces a rapid increase in the concentration of cAMP in the sensory neurons, which reaches a peak within 2-3 min (Bacskai et al., 1993). The facilitation of the nondepressed synapses by PKA involves both a spike duration-independent and a spike duration-dependent process (Fig. 2A) (Gingrich and Byrne, 1984, 1985; Sugita et al., 1992; Klein, 1993, 1994a).

By contrast, the facilitation of depressed synapses recruited for dishabituation relies heavily on PKC (Braha et al., 1990; Ghirardi et al., 1992). With moderate levels of depression, both kinases seem to be equally involved. On the other hand, facilitation of synapses depressed by $90 \%$ is largely attributable to PKC (Fig. 2B).

As with all aspects of behavior, it has been impossible in Aplysia to explore all possible parameters of sensitization, dishabituation, and 5-HT-induced facilitation. The standard protocol used for short-term sensitization has been a single train of stimulation to the body or to a peripheral nerve, typically $10 \mathrm{~Hz}$ for $10-15 \mathrm{sec}$. This stimulation produces shortterm sensitization or presynaptic facilitation in the intact animal or in the isolated ganglion. Alternatively, a single pulse of 5-HT applied from $10 \mathrm{sec}$ to $5 \mathrm{~min}$ is used often to produce short-term facilitation. Long-term sensitization requires four to five repetitions of the sensitizing train or of the pulse of 5-HT, and repetitions typically are spaced with $20 \mathrm{~min}$ intervening separations. Thus, most of the protocols that use 5-HT to examine facilitation have used pulses of $5 \mathrm{~min}$ or less. However, facilitation also is time-dependent (Sugita et al., 1994c). When 5 -HT is present continuously for $>5 \mathrm{~min}(10-30 \mathrm{~min})$, as might be the case in some protocols that produce long-term facilitation, the balance between processes changes. This prolongedexposure protocol has helped us to understand the dynamics of the coordination between PKA and PKC, a coordination that may be particularly important for intermediate durations of memory storage. This is particularly interesting considering the suggestion that $\mathrm{PKC}$ has a role in an intermediate phase that bridges short- and long-term facilitation (Sossin et al., 1994). 
This time dependence of facilitation (Fig. 3) is supported by independent biochemical studies showing that different lengths of exposure to 5-HT lead to the phosphorylation of different sets of substrate proteins. Quantitative two-dimensional PAGE of ${ }^{32} \mathrm{P}$-labeled sensory neurons showed that each of 18 specific proteins found to be significantly phosphorylated after $5 \mathrm{~min}$ exposure to 5-HT also was phosphorylated by application of cAMP, and only 2 of these proteins were phosphorylated also by application of the phorbol ester PDAc (Sweatt and Kandel, 1989). In a separate study, it was found similarly that after 2 min exposure to 5-HT the phosphorylation of one protein was affected by cAMP, whereas none was affected by PDAc (R. Homayouni, J. Byrne, and A. Eskin, unpublished observations). By contrast, after exposure to 5-HT ranging from $25 \mathrm{~min}$ to 1.5 hr, proteins also were affected by PDAc (Homayouni el al., 1995). Thus, whereas the PKA pathway appears to be involved in the early effects of 5-HT on protein phosphorylation, PKC seems to be involved at later times.

\section{AN OVERVIEW}

The first 15 years of studying presynaptic facilitation outlined its role in sensitization and dishabituation in the gillwithdrawal reflex, delineated its presynaptic nature, and documented the participation of $\mathrm{c} \Lambda \mathrm{MP}$ and PKA in ion channel modulation and in the enhancement of transmitter release. The last 15 years of studies have elaborated on the detailed intracellular mechanisms involved. These recent studies have provided evidence for the coordinated participation of two different second-messenger pathways, $\mathrm{PKC}$ and $\mathrm{PKA}$, in regulating the enhancement of transmitter release and have delineated the specific role of each of these second-messenger pathways in its contribution to facilitation. In addition, these recent studies have characterized the two major $\mathrm{K}^{+}$currents that contribute to spike broadening and have led to the discovery that, in addition to spike broadening, presynaptic facilitation involves a direct modulation of one or another step in transmitter mobilization or release.

However, despite the progress made during the last decade in analyzing the mechanisms of short-term presynaptic facilitation using certain specified protocols, the precise quantitative contributions of the various processes that participate in facilitation under a wider range of conditions continue to be difficult to assess. This is because the processes contributing to facilitation, much as those that contribute to hippocampal long-term potentiation (LTP), are highly dependent on the precise pattern of stimulation. In addition, the reagents used so far to isolate and study these processes have been less than ideal. For example, in Aplysia neurons 5-HT leads to the translocation of only one isoform of $\mathrm{PKC}$, a $\mathrm{Ca}^{2+}$-dependent isoform. By contrast, phorbol esters, which have been used to activate PKC, translocate both isoforms. Similarly, spike broadening and the spike broadening-independent modulation of release are complex processes that vary as functions of time and concentration of 5-HT. Also, the processes that take place in the synaptic terminal may differ from those that are measured in the soma. In addition, the relative recruitment of the component processes also may vary as a function of temperature and experimental preparation (intact ganglion or various types of dissociated cell culture). Each of these experimental systems, although significantly related to the other systems it is designed to model qualitatively, nevertheless is likely to differ from the other systems quantitatively in the extent of spatial distribution of receptors and ion channels, complements of biochemical cascades, and surface-to-volume ratios.

It will be particularly informative, therefore, to explore directly the molecular cross-talk between the various second-messenger and protein kinase systems. For example, recent results suggest that PKC can reduce the 5-HT-induced increase in CAMP, perhaps by acting on the receptor coupled to adenylyl cyclase (Sugita et al., 1993). Ilow does this occur? Does PKC activate a $\beta$-adrenergic receptor kinase-like kinase that phosphorylates and desensitizes the 5-HT receptor coupled to adenylyl cyclase? Recent results also indicate that, in addition to PKA and PKC, 5-HT recruits the $\mathrm{Ca}^{2+} /$ calmodulin-dependent protein kinase II (Saitoh and Schwartz, 1983; Nakanishi et al., 1994) and the microtubuleassociated protein kinase (Michael et al., 1995). Finally, it will be important to relate the contribution of these monosynaptic pathways to gill, siphon, and tail withdrawal under a variety of learning conditions.

Despite these quantitative difficulties and the gaps in our knowledge, we believe that the updated models of Figures 2 and 3 accurately describe our current understanding of presynaptic facilitation in at least qualitative terms. As the initial cell biological models of the early 1980 s served as a starting point for a generation of studies on the biophysical level relating the properties of single cells to behavior, we hope that these updated views will stimulate a new round of explorations, this time on a molecular level. Moreover, the finding that at the sensory-to-motor synapse facilitation is state- and time-dependent seems to be emerging as a general feature of synaptic plasticity. For example, synaptic plasticity in the CA1 region of the hippocampus involves multiple kinase and phosphatase systems, and the qualitative nature of the change (long-term depression, depotentiation, or LTP) is dependent on the state of the synapse. Similarly, in LTP there are multiple temporal domains of facilitation (Huang and Kandel, 1994; Huang et al., 1994). Thus, it will be important in the future to determine the molecular logic and behavioral relevance of these state- and time-dependent processes for various types of learning.

\section{REFERENCES}

Abrams TW, Castellucci VF, Camardo ER, Kandel ER, Lloyd PE (1984) Two endogenous neuropeptides modulate the gill and siphon withdrawal reflex in Aplysia by presynaptic facilitation involving cAMPdependent closure of a serotonin-sensitive potassium channel. Proc Natl Acad Sci USA 81:7956-7960.

Augustine GJ (1990) Regulation of transmitter release at the squid giant synapse by presynaptic delayed rectifier potassium current. J Physiol (Lond) 431:343-364.

Bacskai BJ, Hochner B, Mahoaut-Smith M, Adams SR, Kaang B-K, Kandel ER, Tsien RY (1993) Spatially resolved dynamics of cAMP and protein kinase A subunits in Aplysia sensory neurons. Science 260:222-226.

Bailey CH, Chen M (1988a) Long-term memory in Aplysia modulates the total number of varicosities of single identified sensory neurons. Proc Natl Acad Sci USA 85:2372-2377.

Bailey CH, Chen M (1988b) Long-term sensitization in Aplysia increases the number of presynaptic contacts onto the identificd gill motor neuron L7. Proc Natl Acad Sci USA 85:9356-9359.

Bailey CH, Chen M (1988c) Morphological basis of short-term habituation in Aplysia. J Neurosci 8:2452-2459.

Baxter DA, Byrne JH (1989) Serotonergic modulation of two potassium currents in pleural sensory neurons of Aplysia. J Neurophysiol 62:665-679.

Baxter DA, Byrne JH (1990a) Differential effects of cAMP and serotonin on membrane current, action potential duration, and excitability in somata of pleural sensory neurons of Aplysia. J Neurophysiol 64:978-990 
Baxter DA, Byrne JH (1990b) Mathematical modeling of the serotonergic modulation of electrophysiological properties of sensory neurons in Aplysia. Soc Neurosci Abstr 16:1297.

Belkin KJ, Goldstein MJ, Goldsmith BA, Abrams TW (1992) A simula tion approach to evaluating relative contributions of multiple 5-HTmodulated $\mathrm{K}^{+}$currents to spike broadening in Aplysia sensory neurons. Soc Neurosci Abstr 18:713.

Bernier L, Castellucci VF, Kandel ER, Schwartz JH (1982) Facilitatory transmitter causes a selective and prolonged increase in adenosine $3^{\prime} 5^{\prime}$-monophosphate in sensory neurons mediating the gill and siphon withdrawal reflex in Aplysia. J Neurosci 2:1682-1691.

Blumenfeld H, Spira ME, Kandel ER, Siegelbaum SA (1990) Facilitatory and inhibitory transmitters modulate calcium influx during action potentials in Aplysia sensory neurons. Neuron 5:487-499.

Boyle MR, Klein M, Smith SJ, Kandel ER (1984) Serotonin increases intracellular $\mathrm{Ca}^{2+}$ transients in voltage-clamped sensory neurons of Aplysia californica. Proc Natl Acad Sci USA 81:7642-7646.

Braha O (1990) Possible involvement of protcin kinase $C$ in presynaptic facilitation of the sensory-motor synapse of Aplysia. PhD thesis, Columbia University.

Braha O, Dale N, Hochner B, Klein M, Abrams TW, Kandel ER (1990) Second messengers involved in the two processes of presynaptic facilitation that contribute to sensitization and dishabituation in Aplysia sensory neurons. Proc Natl Acad Sci USA 87:2040-2044.

Braha O, Edmonds B, Sacktor T, Kandel ER, Klein M (1993) The contributions of protein kinase $\mathrm{A}$ and protein kinase $\mathrm{C}$ to the actions of 5-HT on L-type $\mathrm{Ca}^{2+}$ current of the sensory neurons in Aplysia. J Neurosci 13:1839-1851.

Brunelli M, Castellucci V, Kandel ER (1976) Synaptic facilitation and behavioral sensitization in Aplysia: possible role of serotonin and cyclic AMP. Science 194:1178-1181.

Byrne JH (1987) Cellular analysis of associative learning. Physiol Rev $67: 329-439$.

Byrne JH, Cleary LJ, Baxter DA (1990) Aspects of the neural and molecular mechanisms of short-term sensitization in Aplysia: modulatory effects of serotonin and cAMP on duration of action potentials, excitability and membrane currents in tail sensory neurons. In: The biology of memory (Squire LR, Lindenlaub E, eds), pp 7-28. New York: Springer.

Byrne IH, 7wartjes R, Homayouni R, Critz S, Eskin A (1993) Roles of second messenger pathways in neuronal plasticity and in learning and memory: insights gained from Aplysia. In: Advances in second messenger and phosphoprotein research, Vol 27 (Nairn AC, Shenolikar S, eds), pp 47-108. New York: Raven.

Canavier CC, Baxter DA, Clark JW, Byrne JH (1991) Simulations of action potentials, transmitter release, and plasticity of sensorimotor synapses in Aplysia. Soc Neurosci Abstr 17:1590.

Carew TJ (1995) A comparison of the mechanistic relationships between development and learning in Aplysia. In: Learning and memory: proceedings of the 23rd Göttingen Neurobiology Conference (Elsner N, Menzel R, eds), pp 83-103. Stuttgart: Verlag.

Carew TJ, Sahley CJ (1986) Invertebrate learning and memory: from behavior to molecules. Annu Rev Neurosci 9:435-487.

Carew TJ, Castellucci VF, Kandel ER (1971) An analysis of dishabituation and sensitization of the gill-withdrawal reflex in Aplysia. Int $\mathrm{J}$ Neurosci 2:79-98.

Carew TJ, Wrighı WG, McCance EF (1989) Development of long-term memory in Aplysia: long-term sensitization is present when short-term sensitization first emerges. Soc Neurosci Abstr 15:1285.

Castellucci VF, Kandel ER (1976) Presynaptic facilitation as a mechanism for behavioral sensitization in Aplysia. Science 194:1176-1178.

Castellucci VF, Kandel ER, Schwartz JH, Wilson FD, Nairn AC, Greengard P (1980) Intracellular injection of the catalytic subunit of cyclic AMP-dependent protein kinase simulates facilitation of transmitter release underlying behavioral sensitization in Aplysia. Proc Natl Acad Sci USA 77:7492-7496.

Castellucci VF, Nairn AC, Greengard P, Schwartz JH, Kandel ER (1982) Inhibitor of adenosine 3,5-monophosphate-dependent protein kinase blocks presynaptic facilitation in Aplysia. J Neurosci 2:1673-1681.

Castellucci VF, Pinsker H, Kupfermann I, Kandel ER (1970) Neuronal mechanisms of habituation and dishabituation of the gill-withdrawal reflex in Aplysia. Science 167:1745-1748.

Cedar H, Schwartz JH (1972) Cyclic AMP in the nervous system of Aplysia californica. II. Effect of serotonin and dopamine. J Gen Physiol 60:570-587.
Cedar H, Kandel FR, Schwartz JH (1972) Cyclic AMP in the nervous system of Aplysia califomica. I. Increased synthesis in response to synaptic stimulation. J Gen Physiol 60:558-569.

Conn PJ, Strong JA, Azhderian EM, Nairn AC, Grcengard P, Kaczmarek LK (1989) Protein kinase inhibitors selectively block phorbol ester- or forskolin-induced changes in excitability of Aplysia neurons. J Neurosci 9:473-479

Critz SD, Baxter DA, Byrne JH (1991) Modulatory effects of serotonin, FMRFamide, and myomodulin on the duration of action potentials, excitability, and membrane currents in tail sensory neurons of Aplysia. J Neurophysiol 66:1912-1926.

Dale N, Kandel ER (1990) Facilitatory and inhibitory transmitters modulate spontaneous transmitter release at cultured Aplysia sensorimotor synapses. J Physiol (Lond) 421:203-222.

Dale N, Kandel ER, Schacher S (1987) Serotonin produces long-term changes in the excitability of Aplysia sensory neurons in culture that depend on new protein synthesis. J Neurosci 7:2232-2238.

Dale N, Schacher S, Kandel ER (1988) Long-term facilitation in Aplysia involves increase in transmitter release. Science 239:282-285.

Edmonds B, Klein M, Kandel ER (1990) Contribution of two types of calcium channels to synaptic transmission and plasticity. Science 250:1142-1147.

Eliot LS, Kandel ER, Siegelbaum SA, Blumenfeld H (1993) Imaging terminals of Aplysia sensory neurons demonstrates role of enhanced $\mathrm{Ca}^{2+}$ influx in presynaptic facilitation. Nature 361:634-637.

Fimptage NJ, Carew TJ (1993) Long-term synaptic facilitation in the absence of short-term facilitation in Aplysia neurons. Science 262:253-256.

Emptage NJ, Carcw TJ (1994) Low concentrations of serotonin facilitate depressed but not non-depressed synaptic potentials from tail sensory neurons of Aplysia. Soc Neurosci Abstr 20:814.

Emptage NJ, Mauelshagen J, Carew TJ (1996) Threshold serotonin concentration required to produce synaptic facilitation differs for depressed and nondepressed synapses in Aplysia sensory neurons. J Neurophysiol, in press.

Frost WN, Castellucci VF, Hawkins RD, Kandel ER (1985) Monosynaptic connections made by the sensory neurons of the gill- and siphonwithdrawal reflex in Aplysia participate in the storage of long-term memory for sensitization. Proc Natl Acad Sci USA 82:8266-8269.

Ghirardi M, Braha O, Hochner B, Montarolo PG, Kandel ER, Dale N (1992) Roles of PKA and PKC in facilitation of evoked and spontaneous transmitter release at depressed and nondepressed synapses in Aplysia sensory neurons. Neuron 9:479-489.

Gingrich KJ, Byrne JH (1984) Simulation of nonassociative and associative neuronal modifications in Aplysia. Soc Neurosci Abstr 10:270.

Gingrich KJ, Byrne JH (1985) Simulation of synaptic depression, posttetanic potentiation, and presynaptic facilitation of synaptic potentials from sensory neurons mediating gill-withdrawal reflex in Aplysia. J Neurophysiol 53:652-659.

Gingrich KJ, Byrne JH (1987) Single-cell neuronal model for associative learning. J Neurophysiol 57:1705-1715.

Gingrich KJ, Baxter DA, Byrne JH (1988) Mathematical model of cellular mechanisms contributing to presynaptic facilitation. Brain Res Bull 21:513-520.

Glanzman DL, Kandel ER, Schacher S (1990) Target-dependent structural changes accompanying long-term synaptic facilitation in Aplysia neurons. Science 249:799-802

Glanzman DL, Mackey SL, Hawkins RD, Dyke AM, Lloyd PE, Kandel ER (1989) Depletion of serotonin in the nervous system of Aplysia reduces the behavioral enhancement of gill withdrawal as well as the heterosynaptic facilitation produced by tail shock. J Neurosci 9:4200)-4213.

Goclet P, Castellucei VF, Schacher S, Kandel ER (1986) The long and the short of long-term memory-a molecular framework. Nature 322:419-422.

Goldsmith BA, Abrams TW (1991) Reversal of synaptic depression by serotonin at Aplysia sensory neuron synapses involves activation of adenylate cyclase. Proc Nall Acad Sci USA 88:9021-9025.

Goldsmith BA, Abrams TW (1992) cAMP modulates multiple $\mathrm{K}^{+}$currents, increasing spike duration and excitability in Aplysia sensory neurons. Proc Natl Acad Sci USA 89:11481-11485.

Hawkins RD, Carew TJ, Kandel ER (1986) Effects of interstimulus interval and contingency on classical conditioning of the Aplysia siphon withdrawal reflex. J Neurosci 6:1695-1701.

Hawkins RD, Kandel ER, Siegelbaum SA (1993) Learning to modulate 
transmitter release: themes and variations in synaptic plasticity. Annu Rev Neurosci 16:625-665.

Hochner B, Kandel ER (1992) Modulation of a transient $\mathrm{K}^{+}$current in the pleural sensory neurons of Aplysia by serotonin and cAMP: implications for spike broadening. Proc Natl Acad Sci USA 89:11476-11480.

Hochner B, Klein M, Schacher S, Kandel ER (1986a) Action potential duration and the modulation of transmitter release from the sensory neurons of Aplysia in presynaptic facilitation and behavioral sensitization. Proc Natl Acad Sci USA 83:8410-8414.

Hochner B, Klein M, Schacher S, Kandel ER (1986b) Additional component in the cellular mechanism of presynaptic facilitation contributes to behavioral dishabituation in Aplysia. Proc Natl Acad Sci USA 83:8794-8798.

Hochner B, Schacher S, Klein M, Kandel ER (1985) Presynaptic facilitation in Aplysia sensory neurons: a process independent of $\mathrm{K}^{+}$current modulation becomes important when transmitter release is depressed. Soc Neurosci Abstr 11:29.

Homayouni R, Byrne JH, Eskin A (1995) Dynamics of protein phosphorylation in sensory neurons of Aplysia. J Neurosci 15:429-438.

Huang YY, Kandel ER (1994) Recruitment of long-lasting and protein kinase A-dependent long-term potentiation in the CA1 region of hippocampus requires repeated tetanization. Learn Memory 1:74-82.

Huang Y-Y, Li X-C, Kandel ER (1994) cAMP contributes to mossy fiber LTP by initiating both a covalently-mediated early phase and macromolecular synthesis-dependent late phase. Cell 79:69-79.

Kandel ER, Schwartz JH (1982) Molecular biology of learning: modulation of transmitter release. Science 218:433-443.

Kandel ER, Tauc L (1965) Mechanism of heterosynaptic facilitation in the giant cell of the abdominal ganglion of Aplysia depilans. J Physiol (Lond) 181:28-47.

Klein M (1993) Differential cyclic AMP dependence of facilitation at Aplysia sensorimotor synapses as a function of prior stimulation: augmentation versus restoration of transmitter release. J Neurosci 13:3793-3801.

Klein M (1994a) Synaptic augmentation by 5-HT at rested Aplysia sensorimotor synapses: independence of action potential prolongation. Neuron 13:159-166.

Klein M (1994b) Distinct component of presynaptic calcium current is increased by cyclic AMP at Aplysia sensorimotor synapses in culture. Soc Neurosci Abstr 20:1073.

Klein M, Kandel ER (1978) Presynaptic modulation of voltagedependent $\mathrm{Ca}^{2+}$ current: mechanism for behavioral sensitization in Aplysia califomica. Proc Natl Acad Sci USA 75:3512-3516.

Klein M, Kandel ER (1980) Mechanism of calcium current modulation underlying presynaptic facilitation and behavioral sensitization in Aplysia. Proc Natl Acad Sci USA 77:6912-6916.

Klein M, Camardo J, Kandel ER (1982) Serotonin modulates a specific potassium current in the sensory neurons that show presynaptic facilitation in Aplysia. Proc Natl Acad Sci USA 79:5713-5717.

Klein M, Hochner B, Kandel ER (1986) Facilitatory transmitters and cAMP can modulate accommodation as well as transmitter release in Aplysia sensory neurons: evidence for parallel processing in a single cell. Proc Natl Acad Sci USA 83:7994-7998.

Klein M, Shapiro E, Kandel ER (1980) Synaptic plasticity and modulation of the calcium current. J Exp Biol 89:117-157.

Kruger KE, Sossin WS, Sacktor TC, Bergold PJ, Beushausen S, Schwartz $\mathrm{JH}$ (1991) Cloning and Characterization of $\mathrm{Ca}^{2+}$-dependent and $\mathrm{Ca}^{2+}$-independent PKCs expressed in Aplysia sensory cells. J Neurosci 11:2303-2313.

Kupfermann I, Castellucci V, Pinsker H, Kandel E (1970) Neuronal correlates of habituation and dishabituation of the gill-withdrawal reflex in Aplysia. Science 167:1743-1745.

Lee WL, Aguirre M, Cleary LJ, Byrne JH (1995) Cellular correlates of long-term sensitization in Aplysia. Soc Neurosci Abstr 21:1680.

Marcus EA, Carew TJ (1990) Differential modulation of excitability and spike duration in the tail sensory neurons of developing Aplysia. Soc Neurosci Abstr 16:20.

Marcus EA, Carew TJ (1992) PKC Activation produces spike broadening in sensory neurons of juvenile Aplysia prior to the development of 5-HT-induced broadening. Soc Neurosci Abstr 18:586.

McGehee DS, Heath MJS, Gelber S, Devay P, Role LW (1996) Nicotine activation of presynaptic receptors on CNS neurons potentiates fast excitatory synaptic transmission. Science 269:1692-1696.
Mercer AR, Emptage NJ, Carew TJ (1991) Pharmacological dissociation of modulatory effects of serotonin in Aplysia sensory neurons. Science 254:1811-1813.

Michacl D, Bartsch D, Ning MM, Baston R, Seger R (1995) Aplysia MAP kinase is activated by serotonin and phosphorylates transcription modulators for long-term facilitation. Soc Neurosci Abstr 21:870.

Mintz I, Korn H (1991) Serotonergic facilitation of quantal release at central inhibitory synapses. J Neurosci 11:3359-3370.

Montarolo PG, Goelet P, Castellucci VF, Morgan J, Kandel ER (1986) A critical period of macromolecular synthesis in long-term heterosynaptic facilitation in Aplysia. Science 234:1249-1254.

Nakanishi K, Zhang F, Baxter DA, Eskin A, Byrne JH (1994) $\mathrm{Ca}^{2+}$ calmodulin-dependent protein kinase II inhibitor KN-62 affects both basal synaptic strength and serotonin-induced facilitation of the sensorimotor synaptic connections in Aplysia. Soc Neurosci Abstr $20: 814$.

Ocorr KA, Byrne JH (1985) Membrane responses and changes in cAMP levels in Aplysia sensory neurons by serotonin, tryptamine, FMRFamide and small cardioactive peptide B (SCPB). Neurosci Lett 55:113-118.

Ocorr KA, Byrne JH (1986) Evidence for separate receptors that mediate parallel effects of serotonin and small cardioactive peptide B (SCPB) on adenylate cyclase in Aplysia californica. Neurosci Lett 70:283-288.

Ocorr KA, Tabata M, Byrne JH (1986) Stimuli that produce sensitization lead to elevation of cyclic $\Lambda$ MP levels in tail sensory neurons of $A$ plysia. Brain Res 371:190-192.

Ocorr KA, Walters ET, Byrne JH (1985) Associative conditioning analog selectively increases cAMP levels of tail sensory neurons in Aplysia. Proc Natl Acad Sci USA 82:2548-2552.

Pieroni JP, Byrne JH (1992) Differential effects of serotonin, FMRFamide, and small cardioactive peptide on multiple, distributed processes modulating sensorimotor synaptic transmission in Aplysia. J Neurosci 12:2633-2647.

Pollock JD, Bernier L, Carmardo JS (1985) Serotonin and cyclic adenosine $3^{\prime} 5^{\prime}$-monophosphate modulate the $S$ potassium current in tail sensory neurons in pleural ganglion of Aplysia. J Neurosci 5:1862-1871.

Rankin CH, Carew TJ (1988) Dishabituation and sensitization emerge as separate processing during development in Aplysia. J Neurosci 8:197-211.

Sacktor TC, Schwartz JH (1990) Sensitizing stimuli cause translocation of protein kinase C in Aplysia sensory neurons. Proc Natl Acad Sci USA 87:2036-2039.

Saitoh T, Schwartz JH (1983) Serotonin alters the subcellular distribution of a $\mathrm{Ca}^{2+} / \mathrm{calmodulin}$-binding protein in neurons of Aplysia. Proc Natl Acad Sci USA 88:6708-6712.

Scholz KP, Byrne JH (1987) Long-term sensitization in Aplysia: biophysical correlates in tail sensory neurons. Science 235:685-687.

Shuster MJ, Camardo JS, Siegelbaum SA, Kandel ER (1985) Cyclic AMP-dependent protein kinase closes the serotonin-sensitive $\mathrm{K}^{+}$channels of Aplysia sensory neurons in cell-free membrane patches. Nature 313:392-395.

Siegelbaum SA, Camardo JS, Kandel ER (1982) Serotonin and cyclic AMP close single $\mathrm{K}^{+}$channels in Aplysia sensory neurons. Nature 299:413-417.

Sossin WS, Schwartz JH (1992) Selective activation of $\mathrm{Ca}^{2+}$-activated PKCs in Aplysia neurons by 5-HT. J Neurosci 12:1160-1168.

Sossin WS, Diaz-Arrastia R, Schwartz JH (1993) Characterization of two isoforms of protein kinase $\mathrm{C}$ in the nervous system in Aplysia californica. J Biol Chem 268:5763-5768.

Sossin WS, Sacktor TC, Schwartz JH (1994) Persistent activation of protein kinase $C$ during the development of long-term facilitation in Aplysia. Learn Memory 1:189-202.

Stark LL, Carew TJ (1994) Serotonergic facilitation of synaptic transmission in juvenile Aplysia. Soc Neurosci Abstr 10:814.

Stark LL, Emptage NJ, Carew TJ (1992) Temporal dissociation of 5-HTinduced spike broadening and excitability in Aplysia sensory neurons. Soc Neurosci Abstr 18:941.

Stark LL, Mercer AR, Emptage NJ, Carew TJ (1995) Pharmacological and kinetic claracterization of two functional classes of serotonergic modulation in Aplysia sensory neurons. J Neurophysiol, in press.

Sugita S, Baxter DA, Byrne JH (1993) Prolonged activation of PKC inhibits serotonin-induced enhancement of excitability in pleural sensory neurons of Aplysia. Soc Neurosci Abstr 19:813. 
Sugita S, Baxter DA, Byrne JH (1994a) Activation of protein kinase C mimics serotonin-induced modulation of a voltage-dependent potassium current in pleural sensory neurons of Aplysia. J Neurophysiol 72:1240-1249.

Sugita S, Baxter DA, Byrne JH (1994b) cAMP-independent effects of 8-(4-parachlorophenylthio)-cyclic AMP on spike duration and membrane currents in pleural sensory neurons of Aplysia. J Neurophysiol $72: 1250-1259$

Sugita S, Baxter DA, Byrne JH (1994c) Spike duration-independent processes may contribute to the rapidly developing component of serotonin- and $\mathrm{PKC}$-induced facilitation of nondepressed tail sensorimotor connections in Aplysia. Soc Neurosci Abstr 20:815.

Sugita S, Goldsmith JR, Baxter DA, Byrne JH (1992) Involvement of protein kinase $\mathrm{C}$ in serotonin-induced spike broadening and synaptic facilitation of sensorimotor connections in Aplysia. J Neurophysiol 68:643-651.
Sweatt JD, Kandel ER (1989) Persistent and transcriptionally-dependent increase in protein phosphorylation in long-term facilitation of Aplysia sensory neurons. Nature 339:51-54.

Walsh JP, Byrne JH (1989) Modulation of a steady-state $\mathrm{Ca}^{2+}$-activated, $\mathrm{K}^{+}$current in tail sensory neurons of Aplysia: role of serotonin and cAMP. J Neurophysiol 61:32-44.

Walters ET, Byrne JH, Carew TJ, Kandel ER (1983) Mechanoafferent neurons innervating the tail of Aplysia. II. Modulation by sensitizing stimulation. J Neurophysiol 50:1543-1559.

White JA, Baxter DA, Byrne JH (1994) Analysis of the modulation by serotonin of a voltage-dependent potassium current in sensory neurons of Aplysia. Biophys J 66:710-718.

Zhang F, Goldsmith JR, Byrne JH (1994) Neural analogue of long-term sensitization training produces long-term ( 24 and $48 \mathrm{~h}$ ) facilitation of the sensory-to-motor neuron connection in Aplysia. J Neurophysiol $72: 778-784$. 